\title{
Electrochemical Sensor based on Nano-Perovskite/Ionic Liquid Crystal Modified Carbon Paste Electrode for Effective Determination of Hydroquinone and Catechol
}

\author{
Ekram H. El-Ads, Nada F. Atta*, Ahmed Galal, Nada A. Eid \\ Chemistry Department, Faculty of Science, Cairo University, 12613 Giza, Egypt \\ *E-mail: anada@sci.cu.edu.eg
}

doi: $10.20964 / 2018.02 .30$

Received: 14 October 2017 / Accepted: 8 December 2017 / Published: 28 December 2017

\begin{abstract}
An effective and facile method for the simultaneous determination of dihydroxy-benzene isomers, hydroquinone "HQ" and catechol "CC", at $\mathrm{NdFeO}_{3}$ nano-perovskite/ionic liquid crystal modified carbon paste electrode in presence of sodium dodecyl sulfate (NFILCCP-SDS) is introduced. The proposed nano-composite offered high current responses and low detection limits due to the inherent catalytic properties of its individual modifiers. The proposed sensor has high electro-catalytic activity toward simultaneous determination of HQ and CC in the linear dynamic range of $10 \mu \mathrm{mol} \mathrm{L}^{-1}$ to 180 $\mu \mathrm{mol} \mathrm{L}{ }^{-1}$ with correlation coefficients 0.989 and 0.989 ; detection limits of $0.118 \mu \mathrm{mol} \mathrm{L}^{-1}$ and 0.252 $\mu \mathrm{mol} \mathrm{L} \mathrm{L}^{-1}$ and quantification limits of $0.392 \mu \mathrm{mol} \mathrm{L}-1$ and $0.840 \mu \mathrm{mol} \mathrm{L}^{-1}$, respectively. Three isomers; $\mathrm{HQ}, \mathrm{CC}$ and resorcinol RC were simultaneously identified with good potential peaks separation. The determination of HQ and CC in presence of interfering species was also successful. Real sample analysis in tap water was achieved with acceptable recovery.
\end{abstract}

Keywords: Hydroquinone; Catechol; Tap water; $\mathrm{NdFeO}_{3}$ perovskite; Carbon paste electrode.

\section{FULL TEXT}

(C) 2018 The Authors. Published by ESG (www.electrochemsci.org). This article is an open access article distributed under the terms and conditions of the Creative Commons Attribution license (http://creativecommons.org/licenses/by/4.0/). 